\title{
Hydroxyl radical in/on illuminated polar snow: formation rates, lifetimes, and steady-state concentrations
}

\author{
Zeyuan Chen ${ }^{1}$, Liang Chu ${ }^{1}$, Edward S. Galbavy ${ }^{1, a}$, Keren Ram ${ }^{1}$, and Cort Anastasio ${ }^{1}$ \\ ${ }^{1}$ Department of Land, Air, and Water Resources, University of California, Davis, CA 95616, USA \\ ${ }^{a}$ now at: NOVA Engineering and Environmental, Panama City Beach, FL 32408, USA \\ Correspondence to: Cort Anastasio (canastasio@ucdavis.edu)
}

Received: 8 February 2016 - Published in Atmos. Chem. Phys. Discuss.: 4 March 2016

Revised: 23 June 2016 - Accepted: 5 July 2016 - Published: 2 August 2016

\begin{abstract}
While the hydroxyl radical $\left({ }^{\bullet} \mathrm{OH}\right)$ in the snowpack is likely a dominant oxidant for organic species and bromide, little is known about the kinetics or steady-state concentrations of ${ }^{\bullet} \mathrm{OH}$ on/in snow and ice. Here we measure the formation rate, lifetime, and concentration of ${ }^{\bullet} \mathrm{OH}$ for illuminated polar snow samples studied in the laboratory and in the field. Laboratory studies show that ${ }^{\bullet} \mathrm{OH}$ kinetics and steady-state concentrations are essentially the same for a given sample studied as ice and liquid; this is in contrast to other photooxidants, which show a concentration enhancement in ice relative to solution as a result of kinetic differences in the two phases. The average production rate of ${ }^{\bullet} \mathrm{OH}$ in samples studied at Summit, Greenland, is 5 times lower than the average measured in the laboratory, while the average ${ }^{\bullet} \mathrm{OH}$ lifetime determined in the field is 5 times higher than in the laboratory. These differences indicate that the polar snows we studied in the laboratory are affected by contamination, despite significant efforts to prevent this; our results suggest similar contamination may be a widespread problem in laboratory studies of ice chemistry. Steady-state concentrations of - OH in clean snow studied in the field at Summit, Greenland, range from $(0.8$ to 3$) \times 10^{-15} \mathrm{M}$, comparable to values reported for midlatitude cloud and fog drops, rain, and deliquesced marine particles, even though impurity concentrations in the snow samples are much lower. Partitioning of firn air ${ }^{\bullet} \mathrm{OH}$ to the snow grains will approximately double the steady-state concentration of snow-grain hydroxyl radical, leading to an average $\left[{ }^{\circ} \mathrm{OH}\right]$ in near-surface, summer Summit snow of approximately $4 \times 10^{-15} \mathrm{M}$. At this concentration, the ${ }^{\bullet} \mathrm{OH}$-mediated lifetimes of organics and bromide in Summit snow grains are approximately 3 days and $7 \mathrm{~h}$,
\end{abstract}

respectively, suggesting that hydroxyl radical is a major oxidant for both species.

\section{Introduction}

Hydroxyl radicals $\left({ }^{\bullet} \mathrm{OH}\right)$ are ubiquitous in the atmosphere and react readily with most organic compounds; as such, they play an important role in chemical processing and in controlling the oxidizing capacity of the troposphere (Grannas et al., 2007b; Thompson and Stewart, 1991). Although ${ }^{\bullet} \mathrm{OH}$ has been studied in atmospheric and terrestrial waters (including cloud and fog drops and surface waters) (Anastasio and McGregor, 2001; Arakaki et al., 2013; Ashton et al., 1995; Herrmann et al., 2010), little is known of ${ }^{\bullet} \mathrm{OH}$ in snowpacks (Beyersdorf et al., 2007; Galbavy et al., 2007).

Snowpacks have two general components: the solid snow grains (and their associated impurities) and the interstitial (firn) air (Bartels-Rausch et al., 2014). From hydrocarbon decay measurements, ${ }^{\bullet} \mathrm{OH}$ concentrations in the near-surface firn air at Summit, Greenland, peak at $1.5 \times$ $10^{6}$ molecules $\mathrm{cm}^{-3}$ in the spring (close to the ambient air value) and $3.2 \times 10^{6}$ molecules $\mathrm{cm}^{-3}$ in July (approximately 20-30\% lower than ambient) (Beyersdorf et al., 2007). There are no measurements of ${ }^{\bullet} \mathrm{OH}$ concentrations in/on snow grains, but some things are known about the production rate of ${ }^{\bullet} \mathrm{OH}\left(P_{\mathrm{OH}}\right)$. Based on laboratory determinations of the quantum yields for ${ }^{\bullet} \mathrm{OH}$ formation from photolysis of hydrogen peroxide $(\mathrm{HOOH})$, nitrate $\left(\mathrm{NO}_{3}^{-}\right)$, and nitrite $\left(\mathrm{NO}_{2}^{-}\right)$, estimated values of $P_{\mathrm{OH}}$ in polar surface snow during summer are on the order of $100-300 \mathrm{nMh}^{-1}$, with nearly all from photolysis of $\mathrm{HOOH}$ (Chu and Anastasio, 2005, 2003; 
France et al., 2007). The only measurements of ${ }^{\bullet} \mathrm{OH}$ formation rates in/on snow grains are at Summit, with summer values typically in the same range as estimated previously and $\mathrm{HOOH}$ accounting for $97 \%$ or more of photoformed ${ }^{\bullet} \mathrm{OH}$ (Anastasio et al., 2007). While the sink for ${ }^{\bullet} \mathrm{OH}$ has not been measured in snow grains, based on snow composition it appears that organic compounds are the dominant ${ }^{\bullet} \mathrm{OH}$ sinks (Anastasio et al., 2007; Grannas et al., 2004). There are also no measurements of the ${ }^{\bullet} \mathrm{OH}$ steady-state concentration in snow grains, which makes it difficult to estimate the importance of ${ }^{\bullet} \mathrm{OH}$ as an oxidant for organics and bromide.

As discussed in these previous studies, ${ }^{\bullet} \mathrm{OH}$ reactions in/on snow are likely an important sink for snowpack trace species, which will influence the lifetimes, toxicities, and transformations of these contaminants. For example, ${ }^{\bullet} \mathrm{OH}$ reacts with snow-grain organic matter to form volatile organic compounds (VOCs) such as formaldehyde, which can be released to the atmosphere (Anastasio et al., 2007; Anastasio and Jordan, 2004; Domine and Shepson, 2002; Grannas et al., 2004; Jacobi et al., 2006). Oxidation by ${ }^{\bullet} \mathrm{OH}$ can also convert snowpack halides (especially $\mathrm{Br}^{-}$) into reactive volatile halogens, such as $\mathrm{Br}_{2}$, which can alter ozone and hydrocarbon chemistry in both the snow interstitial air and the atmospheric boundary layer (Abbatt et al., 2010; Anastasio et al., 2007; Chu and Anastasio, 2005; Grannas et al., 2007b; Pratt et al., 2013; Thomas et al., 2011; Wren et al., 2013). Additionally, ${ }^{\bullet} \mathrm{OH}$ may alter ice core records of past atmospheres by reacting with trace species in snow (Anastasio and Jordan, 2004).

Recent work has shown that the steady-state concentrations of some oxidants can be much higher in/on illuminated ice compared to in the same sample studied as solution (Bower and Anastasio, 2013a, b; Fede and Grannas, 2015). For example, the singlet oxygen concentration in ice can be higher by a factor of approximately 10000 (Bower and Anastasio, 2013a), while the ice concentration of a triplet excited state can be higher by a factor of roughly 100 (Chen and Anastasio, 2016). These enhancements occur because of the freeze-concentration effect, where solutes are excluded to liquid-like regions (LLRs) in/on the ice, resulting in much higher effective concentrations in these small domains (Bower and Anastasio, 2013a, b; Cho et al., 2002; Grannas et al., 2007a). This same freeze-concentration effect is responsible for the enhancement in rates seen for some second-order thermal reactions in ice (Takenaka and Bandow, 2007).

While it has not been measured experimentally, the freezeconcentration effect may also alter ${ }^{\bullet} \mathrm{OH}$ concentrations within snow and ice (compared to the corresponding solution), which would alter the impacts of this important radical. With this in mind, our goals in this work are to (1) measure the steady-state concentration of ${ }^{\bullet} \mathrm{OH}$, and the ${ }^{\bullet} \mathrm{OH}$ kinetics (i.e., its rate of formation and lifetime), in polar snow samples, (2) compare ${ }^{\bullet} \mathrm{OH}$ measurements in samples studied in the laboratory and in the field, and (3) examine how ${ }^{\bullet} \mathrm{OH}$ ki- netics and concentrations vary between solution and ice. To achieve these goals we used a benzoate probe technique to characterize photoformed ${ }^{\bullet} \mathrm{OH}$ in polar snow samples studied in the lab (as solution and ice) and in the field (studied as ice).

\section{Experimental methods}

\subsection{Materials}

Hydrogen peroxide and acetonitrile (Optima) were from Fisher, sodium benzoate (99\%) and 2-nitrobenzaldehyde $(2 \mathrm{NB} ; 98 \%)$ were from Sigma-Aldrich, and $p$ hydroxybenzoate ( $p$-HBA; $98 \%)$ was from TCI America. All chemicals were used as received. Purified water ("Milli-Q water") was obtained from a Milli-Q Plus system $(\geq 18.2 \mathrm{M} \Omega \mathrm{cm})$ with an upstream Barnstead B-Pure cartridge to remove organics; the Milli-Q system does not use UV radiation to mineralize organic contaminants.

\subsection{Snow sample collection}

Surface snow samples (approximately $0-3 \mathrm{~cm}$ depth) were collected from undisturbed areas within the clean-air sectors at Summit, Greenland $\left(72.6^{\circ} \mathrm{N}, 38.5^{\circ} \mathrm{W} ; 3200 \mathrm{~m}\right.$ elevation), and Dome $\mathrm{C}$, Antarctica $\left(75.1^{\circ} \mathrm{S}, 123.4^{\circ} \mathrm{E} ; 3270 \mathrm{~m}\right.$ elevation). For the 2005 Summit samples, snow was removed with polytetrafluoroethylene (PTFE) instruments, set on a $1 \mathrm{~m} \times 1 \mathrm{~m}$ Teflon sheet, mixed, and placed in glass Schott bottles $(100$ or $250 \mathrm{~mL})$. In 2006 and 2007, samples were collected directly into the Schott bottles. See Table S1 in the Supplement for sampling conditions. Samples to be studied in the laboratory were held in cold, dark storage at Summit and Dome $\mathrm{C}$ and shipped frozen to UC Davis, where they were stored in a freezer $\left(-20^{\circ} \mathrm{C}\right)$ for 2 to 26 months prior to being studied. Samples studied in the field at Summit were used within 1 week of collection. The field blank for Summit was prepared using Milli-Q from the field that was frozen in Schott bottles and shipped back to UC Davis with the samples. The Dome C field blank was Milli-Q water shipped from our laboratory, frozen at Dome $\mathrm{C}$, and then shipped back with the samples.

\subsection{Laboratory sample preparation}

Each laboratory sample was studied twice: once to determine the formation rate of ${ }^{\bullet} \mathrm{OH}\left(P_{\mathrm{OH}}\right)$ and once to determine the apparent rate constant for ${ }^{\bullet} \mathrm{OH}$ destruction $\left(k^{\prime} \mathrm{OH}\right)$. For each type of test, the snow sample was first melted overnight in the refrigerator. To determine $P_{\mathrm{OH}}, 200 \mu \mathrm{M}$ benzoate (BA) was added to a portion of the melted sample to scavenge essentially all of the ${ }^{\bullet} \mathrm{OH}$ formed during illumination. For measuring $k_{\mathrm{OH}}^{\prime}$, we took four aliquots of the sample, added $100 \mu \mathrm{M}$ $\mathrm{HOOH}$ to each (to increase the rate of ${ }^{\bullet} \mathrm{OH}$ formation and better determine the ${ }^{\bullet} \mathrm{OH}$ sink), and added a different BA 
concentration (typically between 20 and $200 \mu \mathrm{M}$ ) to each. Samples studied as ice were frozen in a covered, custombuilt, Peltier-cooled freeze chamber at $-10^{\circ} \mathrm{C}$ (Bower and Anastasio, 2013a). Laboratory blanks were prepared in the same way as the samples but with fresh Milli-Q instead of melted snow. Based on recent imaging work (Hullar and Anastasio, 2016), we expect that our laboratory-prepared ice samples contain solutes in concentrated liquid-like regions, often in contact with internal air bubbles, in a (mostly) pure ice matrix.

\subsection{Laboratory container types and cleaning treatments}

We tested three types of sample containers in the lab to explore which would minimize contamination: (1) $1 \mathrm{~mL}$ white PTFE Teflon beakers ( $15 \mathrm{~mm} \mathrm{H}, 8 \mathrm{~mm}$ ID, Fisher Scientific); (2) $4 \mathrm{~mL}$ rectangular quartz cells $(1 \mathrm{~cm}$ path length) with airtight screw caps and Teflon septa (FUV, Spectrocell); and (3) $400 \mu \mathrm{L}$ quartz tubes ( $30 \mathrm{~mm}$ length, $5 \mathrm{~mm}$ ID, $1 \mathrm{~mm}$ wall thickness) custom-made from GE 021 quartz and sealed with white silicone caps. We also explored two methods of extra cleaning for the containers after completing our normal cleaning procedures: (1) adding Milli-Q to the container and illuminating it for $24 \mathrm{~h}$ with $254 \mathrm{~nm}$ radiation in an RPR100 photoreactor equipped with 16 mercury lamps $(25 \mathrm{~W})$ (Southern New England Ultraviolet Company) and (2) the same method but with $100 \mu \mathrm{M} \mathrm{HOOH}$ added to the Milli-Q prior to illumination as a photochemical source of ${ }^{\bullet} \mathrm{OH}$.

\subsection{Laboratory sample illumination and analysis}

For laboratory determinations of ${ }^{\bullet} \mathrm{OH}$ kinetics, we apportioned samples (with added BA or with BA and $100 \mu \mathrm{M}$ $\mathrm{HOOH}$; Sect. 2.3) into cleaned ( $\mathrm{HOOH}+\mathrm{UV}$ ) quartz tubes with silicon caps. Samples were held in a custom-designed, Peltier-cooled chamber illuminated with simulated sunlight (Ram and Anastasio, 2009). The solar simulator simulates total global solar radiation at a solar zenith angle of $48.2^{\circ}$. Prior to illumination, samples were allowed to thermally equilibrate in the illumination system chamber in the dark (30 min for liquid samples and 60-80 min for ice samples). During illumination ${ }^{\circ} \mathrm{OH}$ reacts with BA to form the stable product $p$-HBA. To determine the rate of $p$-HBA formation, $50 \mu \mathrm{L}$ of sample $(10 \mu \mathrm{L}$ for rinse and $40 \mu \mathrm{L}$ for injection) was removed at known times and $p$-HBA was measured using high-performance liquid chromatography (HPLC) with UVVis detection (Anastasio et al., 2007). For ice samples, the entire tube was removed at a given time point. We used the same procedures for laboratory and field samples. Dark control samples were run in parallel in the illumination system chamber, using the same sample and container conditions except that the tube and cap were covered with aluminum foil. Lastly, we measured the photon flux $\left(I_{\lambda}\right)$ in all samples by measuring the direct photodegradation of $4 \mu \mathrm{M}$ of $2 \mathrm{NB}$ $\left(j_{2 \mathrm{NB}}\right)$ in the same type of container and same temperature as that in the sample measurement (Chu and Anastasio, 2003).

\subsection{Field studies}

For experiments at Summit, the snow sample in the sealed Schott bottle was left in a heated building $\left(\sim 10^{\circ} \mathrm{C}\right)$ in the dark to melt during the day. That evening we divided the sample into several portions, added a different concentration of BA $(2-11 \mu \mathrm{M})$ to each, and created ice pellets by freezing $1 \mathrm{~mL}$ aliquots of sample on a PTFE sheet within a trench dug below the Summit Science Lab. (Note that we had planned to add 10 times more BA to the samples but mistakenly made a lower concentration BA stock solution that was not discovered until after the field campaign ended.) After freezing we kept the pellets outdoors (below freezing) in $30 \mathrm{~mL}$ amber glass jars wrapped in aluminum foil until the moment of exposure. To start illumination, we placed the pellets on the snow surface and quickly picked up an ice pellet as the time zero point (Anastasio et al., 2007). Samples were then collected at known times, put into sealed jars, melted in the dark, and analyzed for $p$-HBA and BA using HPLC. For dark samples we used the same pellets but placed under a tub next to the sunlit samples to eliminate illumination. We also simultaneously illuminated blank controls, which were ice pellets made with Milli-Q water (and BA) instead of snow.

\section{$2.7 \cdot O H$ kinetic analysis}

For the laboratory work we studied each sample twice (Sect. 2.3): once to determine the rate of ${ }^{\bullet} \mathrm{OH}$ formation (in a sample portion with added BA) and once to determine the rate constant for ${ }^{\bullet} \mathrm{OH}$ loss (with added $\mathrm{HOOH}$ and BA). In laboratory samples used to determine the formation rate of - $\mathrm{OH}$ we add $200 \mu \mathrm{M}$ BA so that essentially all of ${ }^{\bullet} \mathrm{OH}$ reacted with BA. Under this condition the experimentally measured rate of ${ }^{\bullet} \mathrm{OH}$ formation ( $\left.P_{\mathrm{OH}, \text { exp }}\right)$ is determined as

$P_{\mathrm{OH}, \exp }=P_{p-\mathrm{HBA}} / Y_{p-\mathrm{HBA}}$,

where $P_{p \text {-HBA }}$ is the rate of $p$-HBA formation, determined from the slope of a linear regression of $[p-\mathrm{HBA}]$ vs. illumination time, and $Y_{p \text {-HBA }}$ is the yield of $p$-HBA from the ${ }^{\bullet} \mathrm{OH}$ reaction with $\mathrm{BA}(0.19 \pm 0.0068$ and $0.081 \pm 0.014$ for solution and ice, respectively; Anastasio and McGregor, 2001; Chu and Anastasio, 2003).

In laboratory samples with $100 \mu \mathrm{M}$ of added $\mathrm{HOOH}$ (and different amounts of BA), we determined the apparent rate constant for ${ }^{\bullet} \mathrm{OH}$ destruction, $k^{\prime} \mathrm{OH}$, which is the inverse of the ${ }^{\bullet} \mathrm{OH}$ lifetime $\left(\tau_{\mathrm{OH}}\right)$. This pseudo-first-order rate constant reflects the concentrations and reactivities of all of the - OH sinks in each sample and is equal to the product of the second-order rate constant for each sink $i$ and its concentration, $[i]$, summed over all of the sinks, i.e., $k^{\prime} \mathrm{OH}=$ $\Sigma k_{\mathrm{OH}+i}[i]$. The value of $k^{\prime} \mathrm{OH}$ for each sample is determined from a linear regression of $1 / P_{p \text {-HBA }}$ vs. $1 /[\mathrm{BA}]$ (i.e., the 
"inverse" plot) (Anastasio and McGregor, 2001; Zhou and Mopper, 1990):

$k_{\mathrm{OH}}^{\prime}=k_{\mathrm{BA}+\cdot} \cdot \mathrm{OH} \times($ slope $/ y$ intercept $)$,

where $k_{\mathrm{BA}+} \cdot \mathrm{OH}$ is the second-order rate constant for the reaction of $\mathrm{BA}$ and ${ }^{\bullet} \mathrm{OH}$ (in $\mathrm{M}^{-1} \mathrm{~s}^{-1}$ ), estimated from $k_{\mathrm{BA}+} \cdot \mathrm{OH}=\exp (26.6-(1194.8 / T))$ for both solution and ice samples (Ashton et al., 1995). We subtracted the $k^{\prime} \mathrm{OH}$ contribution from the $100 \mu \mathrm{M} \mathrm{HOOH}$ added to each sample; this value is $4.5 \times 10^{3} \mathrm{~s}^{-1}$ based on a second-order rate constant (Dorfman and Adams, 1973) for ${ }^{\circ} \mathrm{OH}$ and $\mathrm{HOOH}$ of $4.5 \times 10^{7} \mathrm{M}^{-1} \mathrm{~s}^{-1}$. Lastly, we determined the steady-state concentration of ${ }^{\bullet} \mathrm{OH}$ by combining the measured production rate (from the sample without added $\mathrm{HOOH}$ ) and the measured $k_{\mathrm{OH}}^{\prime}$ :

$\left[{ }^{\bullet} \mathrm{OH}\right]_{\exp }=\frac{P_{\mathrm{OH}, \exp }}{k^{\prime} \mathrm{OH}}$.

The experimentally determined values of $P_{\mathrm{OH}, \exp }$ and $\left[{ }^{\bullet} \mathrm{OH}\right]_{\exp }$ (i.e., under the illumination conditions in our laboratory) were then normalized to give the values expected under midday, summer solstice sunlight conditions at Summit:

$$
\begin{aligned}
& P_{\mathrm{OH}, \mathrm{Sum}}=P_{\mathrm{OH}, \exp } \times \frac{j_{2 \mathrm{NB}, \mathrm{Sum}}}{j_{2 \mathrm{NB}, \exp }} \\
& {\left[\bullet^{\bullet} \mathrm{OH}\right]_{\mathrm{Sum}}=\left[\bullet^{\bullet} \mathrm{OH}\right]_{\exp } \times \frac{j_{2 \mathrm{NB}, \mathrm{Sum}}}{j_{2 \mathrm{NB}, \exp }},}
\end{aligned}
$$

where $j_{2 \mathrm{NB}}$, Sum is the rate constant for the loss of the actinometer 2NB under midday, summer solstice sunlight at Summit $\left(0.020 \mathrm{~s}^{-1}\right)$ (Galbavy et al., 2010) and $j_{2 \mathrm{NB} \text {,exp }}$ is the value measured on the day of a given laboratory experiment.

In the field, each sample was only studied once, with different pellets from a given sample containing different concentrations of BA (Sect. 2.6). For each BA concentration in the sample, we determined the rate of $p$-HBA formation from a linear regression of $[p-\mathrm{HBA}]$ vs. illumination time. We then combined these rates in an "inverse" plot of $1 / P_{p \text {-HBA }}$ vs. $1 /[\mathrm{BA}]$ and used it to determine $P_{\mathrm{OH}, \mathrm{Sum}}, k_{\mathrm{OH}}^{\prime}$ (Eq. 2), and $\left[{ }^{\bullet} \mathrm{OH}\right]_{\text {Sum }}$ for the sample:

$P_{\mathrm{OH}, \mathrm{Sum}}=\left(y \text { intercept } \times Y_{p \text {-HBA }}\right)^{-1}$,

$\left[\bullet^{\bullet} \mathrm{OH}\right]_{\mathrm{Sum}}=\left(k_{\mathrm{BA}+} \cdot \mathrm{OH} \times \text { slope } \times Y_{p-\mathrm{HBA}}\right)^{-1}$.

In contrast to our past work (Anastasio et al., 2007), [BA] in the ice pellets was stable and therefore was not needed to normalize $p$-HBA concentrations. Because the rates of formation and steady-state concentrations for the field samples were measured using ambient Summit sunlight, they were not normalized to $j_{2 \mathrm{NB}}$,Sum .

\subsection{Calculated organic carbon concentration}

Organic compounds are likely the dominant sink for ${ }^{\bullet} \mathrm{OH}$ in/on snow grains. As shown by Arakaki et al. (2013), the second-order rate constant for ${ }^{\bullet} \mathrm{OH}$ reaction with organic carbon (in units of $\left.\mathrm{L}(\mathrm{mol} \mathrm{C})^{-1} \mathrm{~s}^{-1}\right)$ is very similar in different atmospheric waters and even in surface waters. These similarities indicate that the apparent ${ }^{\bullet} \mathrm{OH}$ scavenging rate constant in environmental waters is primarily controlled by the organic carbon concentration and is relatively insensitive to differences in the complex mixtures of organic compounds in different samples. This result may be because natural samples likely contain thousands of organic compounds, leading to a relatively robust average scavenging rate constant between different samples. Based on this finding we estimated the concentration of dissolved organic carbon in each sample, $[\mathrm{DOC}]\left(\mathrm{mol} \mathrm{C} \mathrm{L}^{-1}\right)$, using

$[\mathrm{DOC}] \approx \frac{k^{\prime} \mathrm{OH}}{k_{\mathrm{C}, \mathrm{OH}}}$,

where $k^{\prime} \mathrm{OH}$ is the measured pseudo-first-order ${ }^{\bullet} \mathrm{OH}$ scavenging rate constant $\left(\mathrm{s}^{-1}\right)$ and $k_{\mathrm{C}, \mathrm{OH}}$ is the general bimolecular rate constant between ${ }^{\bullet} \mathrm{OH}$ and organic carbon, determined as $(3.8 \pm 1.9) \times 10^{8} \mathrm{~L}(\mathrm{~mol} \mathrm{C})^{-1} \mathrm{~s}^{-1}$ in atmospheric waters (Arakaki et al., 2013).

\section{Results and discussion}

\subsection{Minimizing background contamination for ${ }^{\bullet} \mathrm{OH}$ sinks}

To examine whether our containers or handling may add - $\mathrm{OH}$-scavenging contaminants to our samples, we first performed a series of tests on laboratory Milli-Q blanks in three different types of containers (quartz cells, Teflon beakers, and quartz tubes) with three types of additional cleaning methods (no additional cleaning, $254 \mathrm{~nm}$ UV treatment, $\mathrm{HOOH}+\mathrm{UV}$ treatment). These additional methods were added after finishing with our standard cleaning procedures, which are described below. After the additional cleaning, fresh Milli-Q and $100 \mu \mathrm{M}$ HOOH was added to each container, BA was added at a range of concentrations to different sample aliquots, and the samples were illuminated in order to determine $k^{\prime} \mathrm{OH}$.

The first container type we examined was a $1 \mathrm{~cm}$ rectangular, airtight quartz cell, where the standard cleaning is copious Mill-Q rinsing before and after a rinsing with a 50:50 $\mathrm{MeOH}: 1 \mathrm{M} \mathrm{H}_{2} \mathrm{SO}_{4}$ solution. As shown in Fig. 1, without any additional cleaning, $k^{\prime} \mathrm{OH}$ at $293 \mathrm{~K}$ is $1.1 \times 10^{5} \mathrm{~s}^{-1}$, which is quite high and corresponds to an estimated organic carbon concentration of $300 \mu \mathrm{mol} \mathrm{C} \mathrm{L}{ }^{-1}$ based on Eq. (8). UV irradiation decreases this background by approximately a factor of 2, while the combination of $\mathrm{HOOH}+\mathrm{UV}$ treatment decreases the background by a factor of 10 (Fig. 1). However, because the expensive quartz cells had a tendency to crack upon sample freezing, we next tested Teflon beakers as a container. 

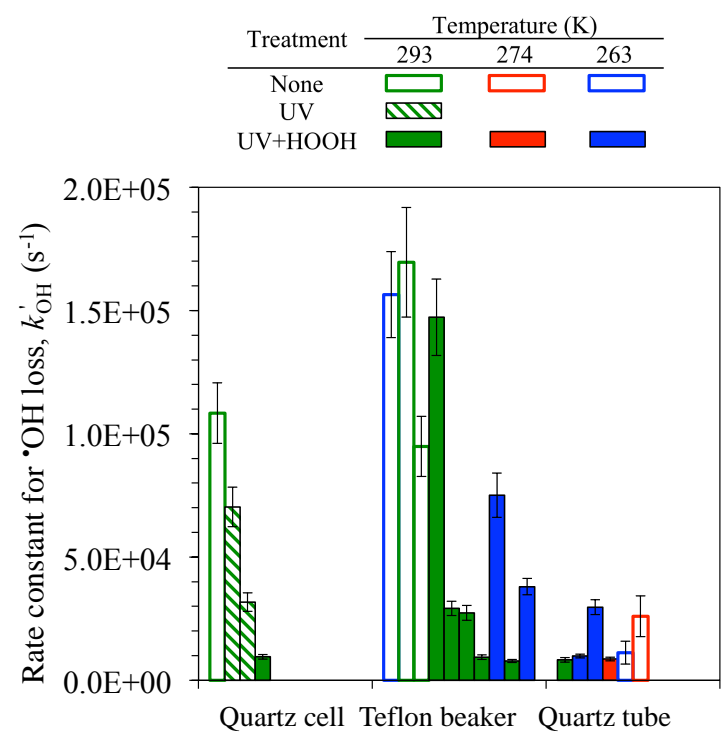

Figure 1. Effects of container type and cleaning on the apparent rate constant for ${ }^{\bullet} \mathrm{OH}$ destruction in Milli-Q blanks. Open bars represent containers with no extra treatment, hatched bars have UV treatment (container with Milli-Q illuminated for $\geq 8 \mathrm{~h}$ with $254 \mathrm{~nm}$ radiation), and solid bars are containers treated with $100 \mu \mathrm{M}$ added $\mathrm{HOOH}$ followed by $\geq 8 \mathrm{~h}$ of UV treatment. Bars within a given treatment are listed in chronological order, from the initial to the final experiment. Error bars represent \pm 1 standard error, based on propagated errors of the linear regression of $1 / p$-HBA vs. $1 /$ [BA] and the second-order rate constant for ${ }^{\bullet} \mathrm{OH}$ with BA.

Ice and solution Milli-Q blanks in Teflon beakers have $k^{\prime} \mathrm{OH}$ values of $(1-1.7) \times 10^{5} \mathrm{~s}^{-1}$ using only our standard cleaning condition, which is Alconox wash, Milli-Q rinse, ethanol rinse, Milli-Q rinse, and then an overnight Milli$\mathrm{Q}$ soak. In contrast, additional $\mathrm{HOOH}+\mathrm{UV}$ treatment can produce ${ }^{\bullet} \mathrm{OH}$ destruction apparent rate constants as low as those seen in the quartz cells $\left(8 \times 10^{3} \mathrm{~s}^{-1}\right)$. However, those in $\mathrm{HOOH}+\mathrm{UV}$-treated Milli-Q blanks studied as ice were approximately 5-10 times higher, suggesting that contaminant gases can adsorb onto the beaker samples and that a closed container is needed.

Therefore, we tested homemade quartz tubes with silicon caps as our third container type. The standard cleaning procedure for these tubes is the same as the Teflon beakers. Figure 1 shows that with additional $\mathrm{UV}+\mathrm{HOOH}$ treatment the quartz tubes can achieve ${ }^{\bullet} \mathrm{OH}$ rate constants as low as the other containers, corresponding to organic carbon concentra-

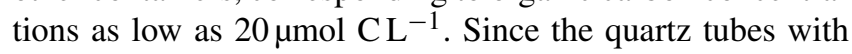
$\mathrm{HOOH}+\mathrm{UV}$ treatment gave low amounts of background - $\mathrm{OH}$ scavengers, were inexpensive, and only occasionally broke upon freezing, we conducted all laboratory measurements of $P_{\mathrm{OH}}$ and $k_{\mathrm{OH}}^{\prime}$ in snow samples using these containers.
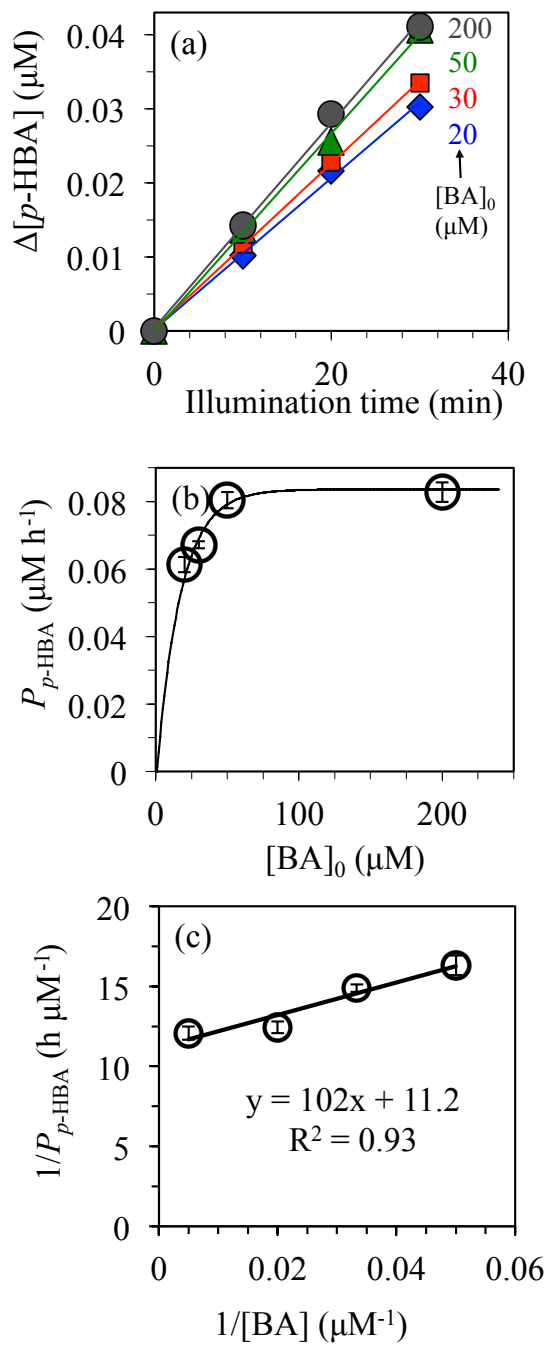

Figure 2. Example of kinetic results for Summit sample 0526 studied in the laboratory. Panel (a) shows the increase in $p$-HBA concentration during illumination in four aliquots of the sample containing different initial BA concentrations $\left([\mathrm{BA}]_{0}\right)$ illuminated for 30 min with simulated sunlight. The diamonds (blue), squares (red), triangles (green), and circles (gray) correspond to BA concentrations of $20,30,50$, and $200 \mu \mathrm{M}$, respectively. The lines represent linear regression fits to data at each BA concentration (with $y$ intercept fixed at zero). Panel (b) shows the measured production rate of $p$-HBA for each BA concentration and the accompanying regression fit. Error bars represent \pm 1 standard error based on the linear regression slopes in panel (a). Panel (c) is the "inverse" plot and linear regression fit, whose slope and $y$ intercept are used to calculate $P_{\mathrm{OH}}, k^{\prime} \mathrm{OH}$, and $\left.{ }^{\bullet} \mathrm{OH}\right]$ (see Sect. 2.7 for more details). Error bars based on \pm 1 standard error calculated in panel (b).

\section{2 $P_{\mathrm{OH}, \mathrm{Sum}}, k_{\mathrm{OH}}^{\prime}$, and $\left[{ }^{\bullet} \mathrm{OH}\right]_{\mathrm{Sum}}$ in laboratory illuminated samples}

Figure 2 shows the results of laboratory experiments conducted on one of the snow samples (Summit 0526). Figure 2a illustrates that the rate of $p$-HBA formation increases with 
increasing $[\mathrm{BA}]$ due to $[\mathrm{BA}]$ intercepting a larger fraction of the photoformed ${ }^{\bullet} \mathrm{OH}$ compared to the natural ${ }^{\bullet} \mathrm{OH}$ scavengers in the sample. The competition between [BA] and other scavengers can be seen more clearly in Fig. $2 b$ where $P_{p \text {-HBA }}$ increases as the $[\mathrm{BA}]$ concentration increases and plateaus at BA concentrations of $50 \mu \mathrm{M}$ and higher, which indicates BA is scavenging most ${ }^{\bullet} \mathrm{OH}$ at and above this concentration. Thus, essentially all ${ }^{\bullet} \mathrm{OH}$ will be scavenged by BA in our samples studied in the laboratory to measure $P_{\mathrm{OH} \text {,exp }}$, where we used $200 \mu \mathrm{M}$ of BA. Lastly, Fig. 2c shows an example of the "inverse" plot used to find $k^{\prime} \mathrm{OH}$ (Eq. 2) in the laboratory samples, which is then combined with $P_{\mathrm{OH}, \mathrm{Sum}}$ (Eq. 4) to determine $\left[{ }^{\bullet} \mathrm{OH}\right]$ (Eqs. 3 and 5).

Figure 3 shows laboratory values of $P_{\mathrm{OH}}$,Sum measured at 263 and $274 \mathrm{~K}$ for three different Summit samples, one Dome C sample, field blanks from Summit and Dome C, and a laboratory blank. Values of $P_{\mathrm{OH}, \text { Sum }}$ are similar at Summit and Dome C (although there is only one Dome C sample) for ice samples $(263 \mathrm{~K})$ and range from approximately 330 to $840 \mathrm{nM} \mathrm{h}^{-1}$, which is somewhat higher than past summer results measured at Summit (130 to $610 \mathrm{nMh}^{-1}$ ) (Anastasio et al., 2007) and higher than the calculated rate of ${ }^{\bullet} \mathrm{OH}$ formation on snow grains from $\mathrm{HOOH}$ photolysis (approximately $250 \mathrm{nM} \mathrm{h}^{-1}$ ) (Chu and Anastasio, 2005). Solution values $(274 \mathrm{~K})$ of $P_{\mathrm{OH}}$,Sum are similar to their corresponding ice values but generally slightly higher; this is likely due in part to the temperature dependence of the ${ }^{\bullet} \mathrm{OH}$ quantum yield from $\mathrm{HOOH}$ photolysis, which is $10 \%$ higher at $274 \mathrm{~K}$ than at $263 \mathrm{~K}$ (Chu and Anastasio, 2005). Blank rates range from 80 to $160 \mathrm{nM} \mathrm{h}^{-1}$ and represent 10 to $40 \%$ of the corresponding sample values.

Figure 4 depicts the apparent rate constant for ${ }^{\bullet} \mathrm{OH}$ destruction $\left(k^{\prime} \mathrm{OH}\right)$ and its inverse - the lifetime of ${ }^{\bullet} \mathrm{OH}\left(\tau_{\mathrm{OH}}\right)$ - for the same set of samples shown in Fig. 3. As was seen for $P_{\mathrm{OH}}$, rate constants for ${ }^{\bullet} \mathrm{OH}$ destruction $\left(k_{\mathrm{OH}}^{\prime}\right)$ are similar between solution and ice for a given sample and are in the same range for the Summit and Dome C samples. On average, $k_{\mathrm{OH}}^{\prime}$ in solution at $274 \mathrm{~K}$ is $20 \%$ higher than the ice value at $263 \mathrm{~K}$. This small difference is probably due to the temperature dependence of the ${ }^{\bullet} \mathrm{OH}$ bimolecular rate constants with organic scavengers. For example, $k_{\mathrm{BA}+} \cdot \mathrm{OH}$ at $274 \mathrm{~K}$ is $20 \%$ higher than the value at $263 \mathrm{~K}$; many of the natural scavengers probably have similar temperature dependence.

$k^{\prime} \mathrm{OH}$ values for the samples without blank correction are in the range of (3.0-7.8) $\times 10^{4} \mathrm{~s}^{-1}$, while blank values are in the range of $(0.83-2.8) \times 10^{4} \mathrm{~s}^{-1}$ (Fig. 4). The average of the blank values is roughly 10,30 , and $60 \%$ of the corresponding average sample values at 293,274 , and $263 \mathrm{~K}$, respectively. This suggests that the sample values without blank correction are upper bounds of the true values. We have not corrected the sample values for the blanks because the blank levels may or may not reflect contamination in the samples. For example, if the blank values are the result of contamination in the Milli-Q water (which was not treated with UV

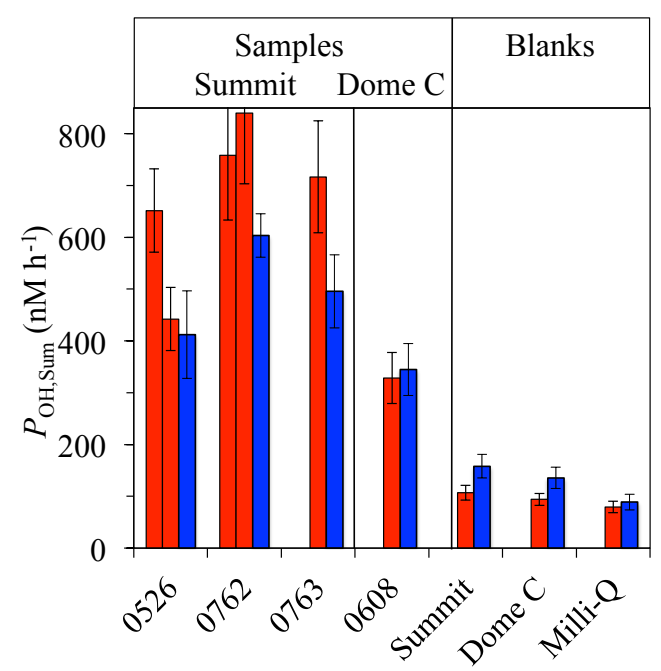

Figure 3. Rate of ${ }^{\bullet} \mathrm{OH}$ formation in Summit and Dome $\mathrm{C}$ snow samples studied as solution ( $274 \mathrm{~K}$, red) and as ice (263 K, blue), after normalization to Summit summer solstice sunlight. Error bars represent \pm 1 standard error, based on propagated errors in the rate of $p$-HBA formation $\left(P_{p \text {-HBA }}\right)$ and $Y_{p \text {-HBA }}$. Sample values are not adjusted for ${ }^{\bullet} \mathrm{OH}$ formation in the blanks.

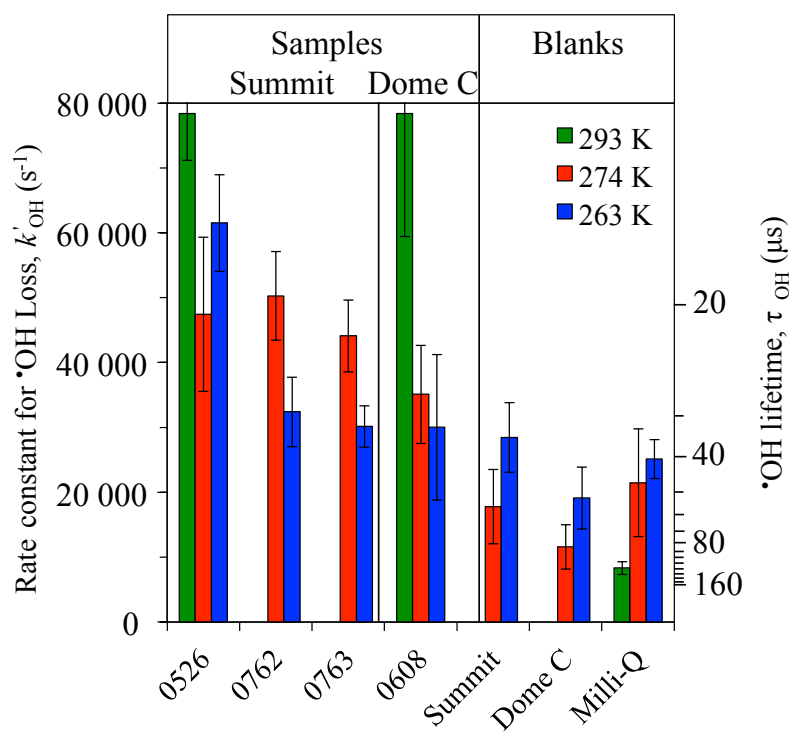

Figure 4. Laboratory-determined apparent rate constant for ${ }^{\bullet} \mathrm{OH}$ destruction (left axis) and the corresponding ${ }^{\bullet} \mathrm{OH}$ lifetime (right axis) in Summit and Dome C snow samples and Milli-Q field and lab blanks (with $100 \mu \mathrm{M}$ added $\mathrm{HOOH}$ ) at $293 \mathrm{~K}$ (green), $274 \mathrm{~K}$ (red), and $263 \mathrm{~K}$ (blue). Error bars represent \pm 1 standard error, based on propagated standard errors (see text for details).

radiation), then this will not affect the samples. On the other hand, if the blank values result from low levels of organics in the illumination containers, then the samples would be expected to have a similar background level. 
Using results from Figs. 3 and 4, we can combine $P_{\mathrm{OH}, \text { Sum }}$ and $k^{\prime} \mathrm{OH}$ to calculate $\left[{ }^{\bullet} \mathrm{OH}\right]_{\mathrm{Sum}}$ (Eq. 7). As shown in Fig. 5, steady-state ${ }^{\bullet} \mathrm{OH}$ concentrations normalized to midday, Summit summer solstice sunlight are $(2-5) \times 10^{-15} \mathrm{M}$ and are similar between ice and solution. These snow concentrations of $\bullet \mathrm{OH}$ are comparable to average values in midlatitude cloud and fog drops, marine particles, and rain, which are generally $(0.5-7) \times 10^{-15} \mathrm{M}$ (Anastasio and McGregor, 2001; Arakaki et al., 2013). This is somewhat surprising since the polar snow samples are much cleaner than the midlatitude drops and particles, which typically have concentrations of contaminants that are orders of magnitude higher; for example, organic carbon concentrations in Davis, CA, fog waters (Anastasio and McGregor, 2001) are approximately 100 times higher than levels in polar snow (see below). In fact, $P_{\mathrm{OH}, \mathrm{Sum}}$ and $k_{\mathrm{OH}}^{\prime}$ are both much smaller in the snow samples (expressed relative to the melted snow volume) than in atmospheric hydrometeors. However, since $\left[{ }^{\bullet} \mathrm{OH}\right]$ is equal to the ratio of these parameters (Eq. 7), its value is very similar across midlatitude drops and particles (Arakaki et al., 2013, 1999) as well as for the snow samples here.

This correlation between ${ }^{\bullet} \mathrm{OH}$ sources and sinks is also responsible for the very similar concentrations of ${ }^{\bullet} \mathrm{OH}$ between the solution and ice results for a given sample (Fig. 5). The - $\mathrm{OH}$ concentration is determined by the balance between its rate of formation and its pseudo-first-order rate constant for loss:

$[\bullet \mathrm{OH}]=\frac{P_{\mathrm{OH}}}{k^{\prime} \mathrm{OH}}$.

For the melted snow samples this is approximately equal to

$\left[\bullet^{\bullet} \mathrm{OH}\right]_{\mathrm{LIQ}} \approx \frac{j\left(\mathrm{HOOH} \rightarrow{ }^{\bullet} \mathrm{OH}\right)[\mathrm{HOOH}]_{\mathrm{LIQ}}}{\sum k_{i+} \cdot \mathrm{OH}[i]_{\mathrm{LIQ}}}$,

where $j\left(\mathrm{HOOH} \rightarrow{ }^{\bullet} \mathrm{OH}\right)$ is the rate constant for ${ }^{\bullet} \mathrm{OH}$ formation from $\mathrm{HOOH}$ photolysis and $i$ represents natural (likely organic) ${ }^{\bullet} \mathrm{OH}$ scavengers. Upon freezing the snow solution, solutes should be mostly excluded to liquid-like regions containing high concentrations of solutes (Bartels-Rausch et al., 2014); for example, at $263 \mathrm{~K}$ the total solute concentration in LLRs is predicted to be $5.4 \mathrm{M}$ (Cho et al., 2002), which represents a freeze-concentration factor of approximately 50000 for a snow sample with an initial (melted) total solute concentration of $100 \mu \mathrm{M}$. As a result of this enhancement in solute concentrations, both $P_{\mathrm{OH}}$ and $k^{\prime} \mathrm{OH}$ in the LLRs should be approximately 50000 times higher than in the melted sample. The resulting expression for $\left[{ }^{\bullet} \mathrm{OH}\right]$ in the LLRs is

$[\bullet \mathrm{OH}]_{\mathrm{LLR}} \approx \frac{j\left(\mathrm{HOOH} \rightarrow{ }^{\bullet} \mathrm{OH}\right)[\mathrm{HOOH}]_{\mathrm{LLR}}}{\sum k_{i+} \bullet \mathrm{OH}[i]_{\mathrm{LLR}}}$.

Since the LLR concentration of a given solute is larger than the initial solution concentration by approximately the freeze-concentration factor $(F)$, we can reexpress Eq. (11) as

$\left[\bullet^{\bullet} \mathrm{OH}\right]_{\mathrm{LLR}} \approx \frac{j\left(\mathrm{HOOH} \rightarrow{ }^{\bullet} \mathrm{OH}\right)[\mathrm{HOOH}]_{\mathrm{LIQ}} F}{\sum k_{i+\bullet} \bullet^{\circ}[i]_{\mathrm{LIQ}} F}$.

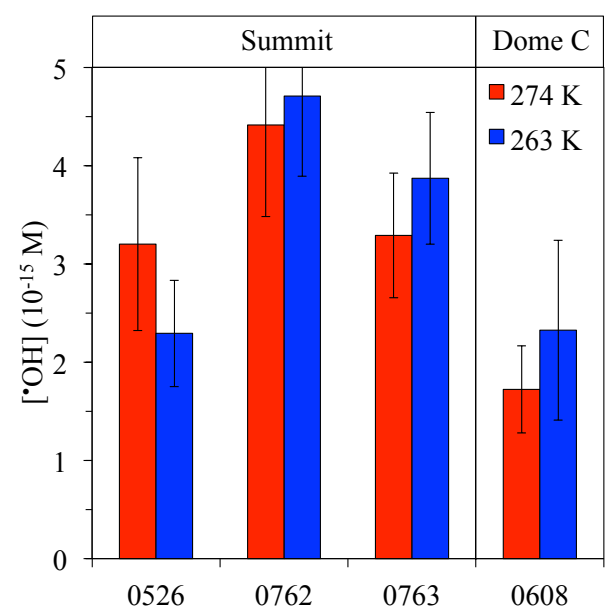

Figure 5. Laboratory-determined steady-state ${ }^{\bullet} \mathrm{OH}$ concentrations in Summit and Dome C snow samples at $274 \mathrm{~K}$ (red) and $263 \mathrm{~K}$ (blue). Error bars represent \pm 1 standard error, based on propagated errors in the slope and $y$ intercept of the "inverse" plots.

The similarities in the ice and solution results in Fig. 5 indicate that the freeze-concentration factor is essentially the same for both the ${ }^{\bullet} \mathrm{OH}$ sources and sinks. Thus, the freezeconcentration factor approximately cancels in Eq. (12) and the steady-state concentration for ${ }^{\bullet} \mathrm{OH}$ in LLRs of ice is essentially the same as in solution. In contrast, in the case of ${ }^{1} \mathrm{O}_{2}^{*}$, the source of singlet oxygen is enhanced by the freezeconcentration factor but the sink (liquid $\mathrm{H}_{2} \mathrm{O}$ ) is essentially the same in LLRs and solution (Bower and Anastasio, 2013a, b). The result is that $\left[{ }^{1} \mathrm{O}_{2}^{*}\right]$ in ice LLRs is enhanced by the freeze-concentration factor, which is on the order of $10^{4}$ or higher for typical polar snows (Bower and Anastasio, 2013a).

We can also use Eqs. (9-12) to gain a better understanding of kinetics in the liquid-like regions. While Figs. 3 and 4 show that $P_{\mathrm{OH}}$ and $k^{\prime} \mathrm{OH}$ are essentially the same for a sample studied as solution or ice, this similarity is somewhat misleading. As shown in the numerator of Eq. (12), the rate of - $\mathrm{OH}$ production in the LLRs should be $F$ times higher than the solution rate. However, since we melt the sample to analyze it, we cannot determine the concentration of photoproduced $p$-HBA in the LLR volume but only in the melted sample volume, which is higher than the LLR volume by a factor of $F$. The same should be true for the apparent rate constant for ${ }^{\bullet} \mathrm{OH}$ loss: as shown in the denominator of Eq. (12), $k^{\prime} \mathrm{OH}$ in the LLR should be $F$ times higher than the solution value, but we do not see this since can only do our analysis in the melted sample. Thus, on a whole (melted) sample volume basis, $P_{\mathrm{OH}}$ and $k^{\prime} \mathrm{OH}$ are the same in solution and ice, but in the native LLR volume, both the rate of ${ }^{\bullet} \mathrm{OH}$ formation and the apparent rate constant for ${ }^{\bullet} \mathrm{OH}$ loss are much higher than in solution. On the other hand, $\left[{ }^{\circ} \mathrm{OH}\right]$ is essentially the same in both ice and solution, regardless of whether we consider 
LLR or total melted sample volume, since it is the ratio of $P_{\mathrm{OH}}$ to $k^{\prime} \mathrm{OH}$.

\section{3 $P_{\mathrm{OH}}, k^{\prime} \mathrm{OH}$, and $\left[{ }^{\bullet} \mathrm{OH}\right]$ in the field}

In addition to the Summit and Dome $\mathrm{C}$ samples that we studied in the laboratory, we also studied a number of snow samples in the field at Summit. Of the 38 field samples (Fig. 6), most were studied only at one BA concentration, but four (experiments 207, 225, 254, and 263) used two to four BA concentrations and thus can be used to derive $P_{\mathrm{OH}}, k^{\prime} \mathrm{OH}$, and $\left[{ }^{\bullet} \mathrm{OH}\right]$. As can be seen from Table $1, P_{\mathrm{OH}}$ values (7 to $200 \mathrm{nM} \mathrm{h}^{-1}$ ) for these four samples studied in the field are, on average, 5 times lower than values for samples studied in the laboratory as ice $\left(350\right.$ to $600 \mathrm{nM} \mathrm{h}^{-1}$ ). While these are different sets of samples, this large difference indicates that the samples studied in the laboratory were contaminated, either from shipping, storage, or handling during the experiments. We can also estimate ${ }^{\bullet} \mathrm{OH}$ production rates for the 34 field samples that were studied at only one BA concentration (i.e., the green diamonds in Fig. 6). Using the average of the slopes from the four experiments with multiple BA concentrations in Fig. $6\left(644 \mathrm{~h} \mu \mathrm{M}^{-1} \mu \mathrm{M}\right)$, we can extrapolate each green diamond in Fig. 6 to its corresponding $y$ intercept and then use Eq. (6) to estimate $P_{\mathrm{OH}}$. The resulting ${ }^{\bullet} \mathrm{OH}$ formation rates range from 9 to $370 \mathrm{nMh}^{-1}$, with an average $( \pm \sigma)$ value of $100 \pm 90 \mathrm{nMh}^{-1}(n=34)$; these values are comparable to $P_{\mathrm{OH}}$ values for the four field samples studied with multiple BA concentrations (Table 1).

Similar to the field-lab relationship in $P_{\mathrm{OH}}, k_{\mathrm{OH}}^{\prime}$ measured in the field $\left((0.2-1) \times 10^{4} \mathrm{~s}^{-1}\right)$ is, on average, 5 times lower than values measured in the laboratory ice samples $\left((3.0-6.2) \times 10^{4} \mathrm{~s}^{-1}\right)$. These large differences in $P_{\mathrm{OH}}$ and $k^{\prime}$ OH between samples studied in the lab and field indicate that transport to Davis, storage, and/or handling in the laboratory added significant amounts of contaminants that are both sources and sinks for ${ }^{\bullet} \mathrm{OH}$. This is also apparent from laboratory measurements of $k^{\prime} \mathrm{OH}$ for the blanks, which are only somewhat smaller than the sample results (Fig. 4). In contrast to the $P_{\mathrm{OH}}$ and $k^{\prime} \mathrm{OH}$ results, values of $\left[{ }^{\circ} \mathrm{OH}\right]$ measured in the field are quite similar to those determined in the laboratory, with average values of $2 \times 10^{-15}$ and $3 \times 10^{-15} \mathrm{M}$, respectively. However, $\left[{ }^{\bullet} \mathrm{OH}\right]$ is only close between the two sets of samples because the contamination in both $P_{\mathrm{OH}}$ and $k^{\prime} \mathrm{OH}$ essentially cancels in the calculation of the steady-state $\bullet \mathrm{OH}$ concentration (Eq. 9).

\subsection{Organic carbon in samples}

We next use our measured values of $k^{\prime}$ OH to estimate concentrations of organic carbon in our samples. As shown in Table S4, organic carbon concentrations in snow samples studied in the laboratory range from 90 to $190 \mu \mathrm{mol} \mathrm{CL} \mathrm{L}^{-1}$, while the field and lab blanks (Milli-Q) range from 20 to $100 \mu \mathrm{mol}$ $\mathrm{CL}^{-1}$. In contrast, estimated organic carbon concentrations

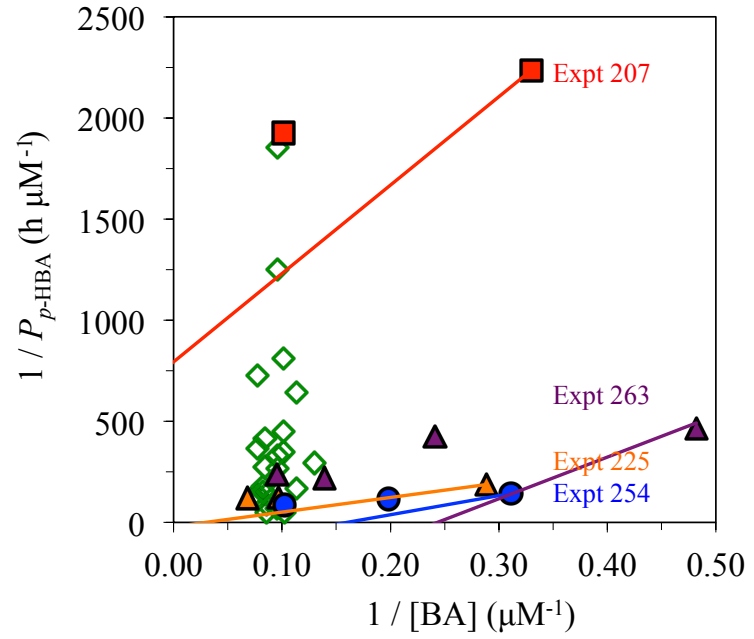

Figure 6. Measurements of $\bullet \mathrm{OH}$ in Summit snow samples studied in the field, including four samples studied with multiple BA concentrations (with experiment number listed). Green hollow diamonds represent the 34 other snow samples that were studied using just one BA concentration.

in the field samples are 5 to $30 \mu \mathrm{mol} \mathrm{CL^{-1 }}$ (Table 1); these much lower DOC values for the field samples are consistent with the idea that there was significant contamination in the samples studied in the lab. Compared to previously reported organic carbon (OC) values, the snow organic carbon concentrations estimated from our field $k^{\prime} \mathrm{OH}$ values are at the lower end of previous results for snow from Summit and Alert and are similar to snow and sea ice values from Barrow (Table 2). In comparison, concentrations in ice core samples tend to be significantly lower, indicating significant mineralization or volatilization of the organic carbon after snow deposition.

\subsection{Implications and uncertainties}

In addition to photolysis of $\mathrm{HOOH}$ and other chromophores in/on snow grains, the transport of firn air ${ }^{\bullet} \mathrm{OH}$ is another source of hydroxyl radical for snow grains. Based on firn air concentrations of ${ }^{\bullet} \mathrm{OH}$ measured at Summit (Beyersdorf et al., 2007), we previously estimated that the rate of the mass transport of firn air ${ }^{\bullet} \mathrm{OH}$ to the snow grains is roughly equal to the rate of $\bullet \mathrm{OH}$ photoformation in/on the snow grains (Anastasio et al., 2007). Thus accounting for gas-to-grain partitioning of ${ }^{\bullet} \mathrm{OH}$ will approximately double our measured values of $P_{\mathrm{OH}, \text { Sum }}$ and $\left[{ }^{\bullet} \mathrm{OH}\right]_{\text {Sum }}$ : based on our field results, the resulting snow-grain steady-state concentrations of - $\mathrm{OH}$ at $263 \mathrm{~K}$ are $(2-6) \times 10^{-15} \mathrm{M}$, with an average of $4 \times$ $10^{-15} \mathrm{M}$. Based on second-order rate constants of ${ }^{\bullet} \mathrm{OH}$ with dissolved organic compounds (typically $1 \times 10^{9} \mathrm{M}^{-1} \mathrm{~s}^{-1}$ ) (Ross et al., 1998) and bromide $\left(1.06 \times 10^{10} \mathrm{M}^{-1} \mathrm{~s}^{-1}\right)(\mathrm{Ze}-$ havi and Rabani, 1972), we estimate $\mathrm{OC}$ and $\mathrm{Br}^{-}$lifetimes as 3 days and $7 \mathrm{~h}$, respectively. This suggests that snow-grain 
Table 1. Summary of snow samples studied in the field at Summit, Greenland.

\begin{tabular}{|c|c|c|c|c|c|c|c|c|}
\hline Date & Expt no. & $\begin{array}{r}\text { Illumination } \\
\text { time }^{\mathrm{a}}\end{array}$ & $\begin{array}{r}T \text { range } \\
(\mathrm{K})\end{array}$ & $\begin{array}{r}P_{\mathrm{OH}} \\
\left(\mathrm{nMh}^{-1}\right)\end{array}$ & $\begin{array}{l}k^{\prime} \mathrm{OH} \\
\left(\mathrm{s}^{-1}\right)\end{array}$ & $\begin{array}{c}\tau_{\mathrm{OH}} \\
(\mu \mathrm{s})\end{array}$ & $\begin{array}{r}{ }^{\left.{ }^{\bullet} \mathrm{OH}\right]} \\
\left(10^{-15} \mathrm{M}\right)\end{array}$ & $\begin{array}{r}{[\mathrm{DOC}]^{\mathrm{b}}} \\
(\mu \mathrm{M})\end{array}$ \\
\hline 30 May 2005 & 207 & $10: 38-16: 01$ & $252-254$ & 7 & $2 \times 10^{3}$ & 500 & 0.8 & 5 \\
\hline 24 June 2005 & 225 & $11: 44-15: 54$ & 259-261 & 100 & $9 \times 10^{3}$ & 100 & 3 & 20 \\
\hline 28 July 2005 & 254 & $10: 38-15: 45$ & $266-268$ & 200 & $1 \times 10^{4}$ & 70 & 3 & 30 \\
\hline 3 August 2005 & 263 & $10: 07-15: 34$ & $260-265$ & 50 & $1 \times 10^{4}$ & 100 & 1 & 30 \\
\hline
\end{tabular}

Table 2. Average dissolved organic carbon concentrations in snow and ice from past reports.

\begin{tabular}{|c|c|c|c|c|}
\hline Type & Location & Time frame & 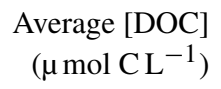 & References \\
\hline \multirow[t]{9}{*}{ Snow } & Summit, Greenland ${ }^{\mathrm{a}}$ & Spring (2001) & 48 & Grannas et al. (2004) \\
\hline & & Summer (2001) & 47 & \\
\hline & & Fall (2001) & 33 & \\
\hline & & Winter (2002) & 36 & \\
\hline & Alert, Nunavut, Canada ${ }^{a}$ & May (2002) & 58 & Grannas et al. (2004) \\
\hline & & February (2002) & 17 & \\
\hline & Barrow, Alaska & February-April (2009) & 20 & Beine et al. (2012) \\
\hline & Taylor Valley, Antarctica ${ }^{a}$ & & $<8$ & Lyons et al. (2007) \\
\hline & Alberta, Canada ${ }^{b}$ & October (1999) & 23,34 & Lafreniere and Sharp (2004) \\
\hline \multirow[t]{8}{*}{ Ice cores } & Col du Dôme & $1850-1976$ & $9.6-25.5^{c}$ & Legrand et al. (2007) \\
\hline & Vostok, Antarctica & 9970 BP & 0.43 & Preunkert et al. (2011) \\
\hline & D47, Antarctica & $9970 \mathrm{BP}$ & 0.14 & Preunkert et al. (2011) \\
\hline & South Pole & $1010 \mathrm{BP}$ & 0.62 & Preunkert et al. (2011) \\
\hline & Summit, Greenland & Winter (1020) & 0.8 & Preunkert et al. (2011) \\
\hline & & Summer (1020) & 3 & \\
\hline & Mont Blanc, French Alps & Winter (1925-1936) & 3.8 & Preunkert et al. (2011) \\
\hline & & Summer (1925-1936) & 8.2 & \\
\hline Sea ice & Barrow, Alaska & & 26 & Beine et al. (2012) \\
\hline
\end{tabular}

- $\mathrm{OH}$ is significant in the transformation of both snowpack organics and bromide, resulting in emissions of both volatile organic compounds and reactive halogen gases (Anastasio et al., 2007; Anastasio and Robles, 2007).

There are several important uncertainties in our results. Perhaps the most important is the uncertain impact of melting the snow samples and refreezing them as ice pellets, which is required in order to add the ${ }^{\bullet} \mathrm{OH}$ probe. This likely alters the partitioning of solutes between the different ice reservoirs, which could change the mixing and colocation of solutes. The most important change in partitioning may be for $\mathrm{HOOH}$, which is the dominant source of snow-grain ${ }^{\bullet} \mathrm{OH}$ (Anastasio et al., 2007; Chu and Anastasio, 2005) and is thought to be present in the bulk ice of surface snow (Jacobi et al., 2004; Neftel et al., 1984). Our sample preparation probably moves $\mathrm{HOOH}$ from the bulk ice matrix to liquidlike regions (Hullar and Anastasio, 2016); this may increase the rate constant for $\mathrm{HOOH}$ photolysis (and thus the steadystate concentration of ${ }^{\bullet} \mathrm{OH}$ ) by roughly a factor of 2 or 3 since $\mathrm{HOOH}$ photolysis in LLRs (Chu and Anastasio, 2005) appears to be more rapid than in bulk ice (Beine et al., 2012). The change in solute locations may also affect the mixing state of solutes, possibly combining species that were initially separate or possibly having the opposite effect. The potential impact of this movement is highly uncertain. Given these potential alterations in solute location and mixing state associated with the melting and refreezing required for the benzoate probe method, our field measurements should be, at present, considered a first-order estimate of hydroxyl radical kinetics in natural snow. While our results are the first experimental determinations of the ${ }^{\bullet} \mathrm{OH}$ sink and steady-state concentration in snow samples, we hope that future developments include a snow-grain ${ }^{\bullet} \mathrm{OH}$ technique that does not disturb snow morphology or solute location. 


\section{Conclusion}

We have made the first complete measurements of ${ }^{\bullet} \mathrm{OH}$ kinetics and steady-state concentrations in illuminated snow samples. For a given sample, we find that ${ }^{\bullet} \mathrm{OH}$ concentrations are essentially the same whether the sample is studied as ice or liquid; the same is true for ${ }^{\bullet} \mathrm{OH}$ production rates and - $\mathrm{OH}$ lifetimes. This lack of enhancement on ice is different from what we have found for singlet molecular oxygen and triplet excited states, both of which are enhanced by orders of magnitude in/on ice compared to in solution.

Production rates of ${ }^{\bullet} \mathrm{OH}$ in samples studied at Summit during summer range between approximately 10 and $200 \mathrm{nM} \mathrm{h}^{-1}$, similar to previously measured and modeled rates. The lifetime of ${ }^{\bullet} \mathrm{OH}$ in these samples is on the order of 70 to $500 \mu$ s, corresponding to organic carbon concentrations of 30 to $5 \mu \mathrm{mol} \mathrm{CL^{-1 }}$. The ${ }^{\bullet} \mathrm{OH}$ concentrations in nearsurface snow at Summit are $(2-6) \times 10^{-15} \mathrm{M}$, with approximately equal contributions from photolysis of snow-grain impurities (mostly $\mathrm{HOOH}$ ) and partitioning of ${ }^{\bullet} \mathrm{OH}$ from the firn air. Compared to these samples studied in the field, samples studied in the laboratory show higher ${ }^{\bullet} \mathrm{OH}$ production rates and lower ${ }^{\bullet} \mathrm{OH}$ lifetimes, both as a result of contaminants, despite significant efforts to minimize contamination. Similar contamination may be important for many laboratory studies of snow chemistry and should be characterized when possible. Based on our field measurements, hydroxyl radical in/on deposited snow grains and on atmospheric snow and ice likely plays an important role in the transformation of organic compounds and bromide. These ${ }^{\bullet} \mathrm{OH}$-mediated reactions will release volatile organic compounds and reactive bromine species to the atmospheric boundary layer, leading to ozone depletion, mercury oxidation, and alterations to $\mathrm{HO}_{x}$ chemistry.

\section{Data availability}

Data are available in the Supplement.

\section{The Supplement related to this article is available online at doi:10.5194/acp-16-9579-2016-supplement.}

Author contributions. Liang Chu and Cort Anastasio designed and carried out the laboratory sample experiments. Edward S. Galbavy, Keren Ram, and Cort Anastasio designed and carried out the field sample experiments. Zeyuan Chen and Cort Anastasio wrote the manuscript with contributions from Liang Chu.

Acknowledgements. We dedicate this work to the memory of Harry Beine, our friend and colleague, who traveled the world to explore the chemistry of Earth's air and snow. The authors thank the National Science Foundation and the Greenland Home Rule Ministry of Environment and Nature for granting us permission to do research at Summit, Greenland. We also thank Barry Lefer, Bernhard Stauffer, Karen Guldbaek Schmidt, and Manuel Hutterli for snow samples; VECO Polar for superb logistical support; and Ted Hullar for editorial help. Funding for this work was provided by the National Science Foundation (grants 0455055 and 1214121).

Edited by: C. Hoyle

Reviewed by: two anonymous referees

\section{References}

Abbatt, J., Oldridge, N., Symington, A., Chukalovskiy, V., McWhinney, R. D., Sjostedt, S., and Cox, R. A.: Release of Gas-Phase Halogens by Photolytic Generation of $\mathrm{OH}$ in Frozen Halide-Nitrate Solutions: An Active Halogen Formation Mechanism?, J. Phys. Chem. A, 114, 6527-6533, 2010.

Anastasio, C. and Jordan, A. L.: Photoformation Of Hydroxyl Radical And Hydrogen Peroxide In Aerosol Particles From Alert, Nunavut: Implications For Aerosol And Snowpack Chemistry In The Arctic, Atmos. Environ., 38, 1153-1166, 2004.

Anastasio, C. and McGregor, K. G.: Chemistry Of Fog Waters In California's Central Valley: 1. In Situ Photoformation Of Hydroxyl Radical And Singlet Molecular Oxygen, Atmos. Environ., 35, 1079-1089, 2001.

Anastasio, C. and Robles, T.: Light Absorption By Soluble Chemical Species In Arctic And Antarctic Snow, J. Geophys. Res.Atmos., 112, D24304, doi:10.1029/2007jd008695, 2007.

Anastasio, C., Galbavy, E. S., Hutterli, M. A., Burkhart, J. F., and Friel, D. K.: Photoformation Of Hydroxyl Radical On Snow Grains At Summit, Greenland, Atmos. Environ., 41, 5110-5121, 2007.

Arakaki, T., Miyake, T., Shibata, M., and Sakugawa, H.: Photochemical Formation And Scavenging Of Hydroxyl Radical In Rain And Dew Waters, Nippon Kagaku Kaishi, 1999, 335-340, 1999.

Arakaki, T., Anastasio, C., Kuroki, Y., Nakajima, H., Okada, K., Kotani, Y., Handa, D., Azechi, S., Kimura, T., Tsuhako, A., and Miyagi, Y.: A General Scavenging Rate Constant for Reaction of Hydroxyl Radical with Organic Carbon in Atmospheric Waters, Environ. Sci. Technol., 47, 8196-8203, 2013.

Ashton, L., Buxton, G. V., and Stuart, C. R.: TemperatureDependence Of The Rate Of Reaction Of OH With Some Aromatic-Compounds In Aqueous-Solution - Evidence For The Formation Of A Pi-Complex Intermediate, J. Chem. Soc. Faraday T., 91, 1631-1633, 1995.

Bartels-Rausch, T., Jacobi, H.-W., Kahan, T. F., Thomas, J. L., Thomson, E. S., Abbatt, J. P. D., Ammann, M., Blackford, J. R., Bluhm, H., Boxe, C., Domine, F., Frey, M. M., Gladich, I., Guzmán, M. I., Heger, D., Huthwelker, Th., Klán, P., Kuhs, W. F., Kuo, M. H., Maus, S., Moussa, S. G., McNeill, V. F., Newberg, J. T., Pettersson, J. B. C., Roeselová, M., and Sodeau, J. R.: A review of air-ice chemical and physical interactions (AICI): liquids, quasi-liquids, and solids in snow, Atmos. Chem. Phys., 14, 1587-1633, doi:10.5194/acp-14-1587-2014, 2014. 
Beine, H., Anastasio, C., Domine, F., Douglas, T., Barret, M., France, J., King, M., Hall, S., and Ullmann, K.: Soluble Chromophores In Marine Snow, Seawater, Sea Ice And Frost Flowers Near Barrow, Alaska, J. Geophys. Res.-Atmos., 117, D00R15, doi:10.1029/2011jd016650, 2012.

Beyersdorf, A. J., Blake, N. J., Swanson, A. L., Meinardi, S., Dibb, J. E., Sjostedt, S., Huey, G., Lefer, B., Rowland, F. S., and Blake, D. R.: Hydroxyl Concentration Estimates In The Sunlit Snowpack At Summit, Greenland, Atmos. Environ., 41, 5101-5109, 2007.

Bower, J. P. and Anastasio, C.: Measuring A 10 000-Fold Enhancement Of Singlet Molecular Oxygen $\left({ }^{1} \mathrm{O}_{2}^{*}\right)$ Concentration On Illuminated Ice Relative To The Corresponding Liquid Solution, Atmos. Environ., 75, 188-195, 2013a.

Bower, J. P. and Anastasio, C.: Using Singlet Molecular Oxygen To Probe The Solute And Temperature Dependence Of Liquid-Like Regions In/On Ice, J. Phys. Chem. A, 117, 6612-6621, 2013 b.

Chen, Z. and Anastasio, C.: Concentrations Of A Triplet Excited State Are Enhanced In Illuminated Ice, in preparation, 2016.

Cho, H., Shepson, P. B., Barrie, L. A., Cowin, J. P., and Zaveri, R.: NMR Investigation Of The Quasi-Brine Layer In Ice/Brine Mixtures, J. Phys. Chem. B, 106, 11226-11232, 2002.

Chu, L. and Anastasio, C.: Quantum Yields Of Hydroxyl Radical And Nitrogen Dioxide From The Photolysis Of Nitrate On Ice, J. Phys. Chem. A, 107, 9594-9602, 2003.

Chu, L. and Anastasio, C.: Formation Of Hydroxyl Radical From The Photolysis Of Frozen Hydrogen Peroxide, J. Phys. Chem. A, 109, 6264-6271, 2005.

Domine, F. and Shepson, P. B.: Air-Snow Interactions And Atmospheric Chemistry, Science, 297, 1506-1510, 2002.

Dorfman, L. M. and Adams, G. E.: Reactivity of the hydroxyl radical in aqueous solutions. Report No. NSRDS-NBS-46, National Standard Reference Data System, National Bureau of Standards, U.S. Department of Commerce, Gaithersburg, MD, USA, 1973.

Fede, A. and Grannas, A. M.: Photochemical Production of Singlet Oxygen from Dissolved Organic Matter in Ice, Environ. Sci. Technol., 49, 12808-12815, 2015.

France, J. L., King, M. D., and Lee-Taylor, J.: Hydroxyl (OH) Radical Production Rates In Snowpacks From Photolysis Of Hydrogen Peroxide $\left(\mathrm{H}_{2} \mathrm{O}_{2}\right)$ And Nitrate $\left(\mathrm{NO}_{3}^{-}\right)$, Atmos. Environ., 41, 5502-5509, 2007.

Galbavy, E. S., Anastasio, C., Lefer, B. L., and Hall, S. R.: Light Penetration In The Snowpack At Summit, Greenland: Part I Nitrite And Hydrogen Peroxide Photolysis, Atmos. Environ., 41, 5077-5090, 2007.

Galbavy, E. S., Ram, K., and Anastasio, C.: 2-Nitrobenzaldehyde As A Chemical Actinometer For Solution And Ice Photochemistry, J. Photochem. Photobio. A, 209, 186-192, 2010.

Grannas, A. M., Shepson, P. B., and Filley, T. R.: Photochemistry And Nature Of Organic Matter In Arctic And Antarctic Snow, Global Biogeochem. Cy., 18, GB1006, doi:10.1029/2003gb002133, 2004.

Grannas, A. M., Bausch, A. R., and Mahanna, K. M.: Enhanced Aqueous Photochemical Reaction Rates After Freezing, J. Phys. Chem. A, 111, 11043-11049, 2007a.

Grannas, A. M., Jones, A. E., Dibb, J., Ammann, M., Anastasio, C., Beine, H. J., Bergin, M., Bottenheim, J., Boxe, C. S., Carver, G., Chen, G., Crawford, J. H., Dominé, F., Frey, M. M., Guzmán, M. I., Heard, D. E., Helmig, D., Hoffmann, M. R., Honrath, R.
E., Huey, L. G., Hutterli, M., Jacobi, H. W., Klán, P., Lefer, B., McConnell, J., Plane, J., Sander, R., Savarino, J., Shepson, P. B., Simpson, W. R., Sodeau, J. R., von Glasow, R., Weller, R., Wolff, E. W., and Zhu, T.: An overview of snow photochemistry: evidence, mechanisms and impacts, Atmos. Chem. Phys., 7, 43294373, doi:10.5194/acp-7-4329-2007, 2007b.

Herrmann, H., Hoffmann, D., Schaefer, T., Brauer, P., and Tilgner, A.: Tropospheric Aqueous-Phase Free-Radical Chemistry: Radical Sources, Spectra, Reaction Kinetics and Prediction Tools, Chemphyschem, 11, 3796-3822, 2010.

Hullar, T. and Anastasio, C.: Direct visualization of solute locations in laboratory ice samples, The Cryosphere Discuss., doi:10.5194/tc-2015-197, in review, 2016.

Jacobi, H. W., Bales, R. C., Honrath, R. E., Peterson, M. C., Dibb, J. E., Swanson, A. L., and Albert, M. R.: Reactive trace gases measured in the interstitial air of surface snow at Summit, Greenland, Atmos. Environ., 38, 1687-1697, 2004.

Jacobi, H. W., Annor, T., and Quansah, E.: Investigation Of The Photochemical Decomposition Of Nitrate, Hydrogen Peroxide, And Formaldehyde In Artificial Snow, J. Photochem. Photobio. A, 179, 330-338, 2006.

Lafreniere, M. J. and Sharp, M. J.: The Concentration And Fluorescence Of Dissolved Organic Carbon (DOC) In Glacial And Nonglacial Catchments: Interpreting Hydrological Flow Routing And DOC Sources, Arct. Antarct. Alp. Res., 36, 156-165, 2004.

Legrand, M., Preunkert, S., Schock, M., Cerqueira, M., KasperGiebl, A., Afonso, J., Pio, C., Gelencser, A., and DombrowskiEtchevers, I.: Major 20th Century Changes Of Carbonaceous Aerosol Components (EC, WINOC, DOC, HULIS, Carboxylic Acids, And Cellulose) Derived From Alpine Ice Cores, J. Geophys. Res.-Atmos., 112, D23S11, doi:10.1029/2006jd008080, 2007.

Lyons, W. B., Welch, K. A., and Doggett, J. K. : Organic Carbon In Antarctic Snow, Geophys. Res. Lett., 34, L02501, doi:10.1029/2006g1028150, 2007.

Neftel, A., Jacob, P., and Klockow, D.: Measurement of hydrogen peroxide in polar ice samples, Nature, 311, 43-45, 1984.

Pratt, K. A., Custard, K. D., Shepson, P. B., Douglas, T. A., Pohler, D., General, S., Zielcke, J., Simpson, W. R., Platt, U., Tanner, D. J., Huey, L. G., Carlsen, M., and Stirm, B. H.: Photochemical Production Of Molecular Bromine In Arctic Surface Snowpacks, Nat. Geosci., 6, 351-356, 2013.

Preunkert, S., Legrand, M., Stricker, P., Bulat, S., Alekhina, I., Petit, J. R., Hoffmann, H., May, B., and Jourdain, B.: Quantification of Dissolved Organic Carbon at Very Low Levels in Natural Ice Samples by a UV-Induced Oxidation Method, Environ. Sci. Technol., 45, 673-678, 2011.

Ram, K. and Anastasio, C.: Photochemistry Of Phenanthrene, Pyrene, And Fluoranthene In Ice And Snow, Atmos. Environ., 43, 2252-2259, 2009.

Ross, A. B., Mallard, W. G., Helman, W. P., Buxton, G. V., Huie, R. E., and Neta, P.: NDRL-NIST solution kinetics database, ver. 3.0, Notre Dame Radiation Laboratory, Notre Dame, IN and National Institute of Standards and Technology, Gaithersburg, MD, available at: http://kinetics.nist.gov/solution/ (last access: November 2015), 1998.

Takenaka, N. and Bandow, H.: Chemical Kinetics Of Reactions In The Unfrozen Solution Of Ice, J. Phys. Chem. A, 111, 87808786, 2007. 
Thomas, J. L., Stutz, J., Lefer, B., Huey, L. G., Toyota, K., Dibb, J. E., and von Glasow, R.: Modeling chemistry in and above snow at Summit, Greenland - Part 1: Model description and results, Atmos. Chem. Phys., 11, 4899-4914, doi:10.5194/acp-11-48992011, 2011.

Thompson, A. M. and Stewart, R. W.: Effect Of Chemical-Kinetics Uncertainties On Calculated Constituents In A Tropospheric Photochemical Model, J. Geophys. Res.-Atmos., 96, 1308913108, 1991.

Wren, S. N., Donaldson, D. J., and Abbatt, J. P. D.: Photochemical chlorine and bromine activation from artificial saline snow, Atmos. Chem. Phys., 13, 9789-9800, doi:10.5194/acp-13-97892013, 2013.
Zehavi, D. and Rabani, J.: Oxidation Of Aqueous Bromide Ions By Hydroxyl Radicals - Pulse Radiolytic Investigation, J. Phys. Chem., 76, 312-319, 1972.

Zhou, X. L. and Mopper, K.: Determination Of Photochemically Produced Hydroxyl Radicals In Seawater And Fresh-Water, Mar. Chem., 30, 71-88, 1990. 